\title{
DIREITO HOMOAFETIVO COMO TEMA TRANSVERSAL NO NOVO ENSINO JURÍDICO SUPERIOR
}

\author{
Homoaffective Rights as a Transversal Theme in New Higher Legal \\ Education
}

\author{
Germana Parente Neiva Belchior \\ Doutora em Direito pela Universidade Federal de Santa Catarina (UFSC) \\ Professora na Graduação e no Programa de Pós-Graduação \\ em Direito do Centro Universitário 7 de Setembro, Fortaleza-CE, Brasil \\ germana_belchior@yahoo.com.br/germana.belchior@uni7.edu.br \\ (D) https://orcid.org/0000-0003-1870-8958 \\ Marcos Heleno Lopes Oliveira \\ Mestrando em Direito Privado pelo Centro \\ Universitário 7 de Setembro (UNI7), Fortaleza-CE, Brasil \\ marcoshlo@bol.com.br \\ https://orcid.org/0000-0001-5619-0577
}

A lista completa com informações dos autores está no final do artigo

\section{RESUMO}

Qual a relevância e a viabilidade da inclusão do Direito Homoafetivo como tema transversal nas disciplinas ministradas no curso de graduação em Direito, conforme as novas diretrizes curriculares estabelecidas pela Resolução CES/CNE 5/2018? A homoafetividade, a diversidade sexual e a identidade de gênero são características resultantes da forma plural de se manifestar da sexualidade humana e possuem reflexos no sistema jurídico normatizador da vida em sociedade, independentemente do ramo do Direito. Assim sendo, existe a necessidade do estudo transversal na graduação em Direito das questões jurídicas relacionadas à homoafetividade, uma vez que essas questões são realidade social vinculada às mais diversas áreas de atuação da ciência jurídica. As ferramentas disponibilizadas pela Resolução CES/CNE 5/2018 viabilizam o aprendizado dos assuntos ligados às minorias sexuais, por meio da conexão dinâmica desses temas com as diversas disciplinas da grade curricular da graduação em Direito. A perspectiva metodológica escolhida tem por base o pensamento complexo. Há a prevalência de resultados sistêmicos, privilegiando a inter e a transdisciplinaridade dos ramos do Direito e das demais áreas do conhecimento humano. Com base na doutrina, na jurisprudência e no sistema legislativo, o trabalho revela a função transdisciplinar do Direito Homoafetivo na graduação em Direito, enquanto tema transversal, e sua contribuição para a formação de competências necessárias à vida acadêmica, profissional e familiar do jurista contemporâneo, fortalecendo a tolerância e o respeito na sociedade.

PALAVRAS-CHAVE: Resolução CES/CNE 5/2018. Ensino jurídico superior. Direito Homoafetivo. Diversidade sexual e de gênero. Transdisciplinaridade.

\begin{abstract}
What is the relevance and feasibility of including Homoaffective Rights as a cross-curricular theme in the subjects taught in the undergraduate course in Law, according to the new curricular guidelines established by Resolution CES/CNE $5 / 2018$ ? Homoaffectivity, sexual diversity and gender identity are characteristics resulting from the plural way of manifesting human sexuality and have reflexes in the normative legal system of life in society, regardless of the branch of law. Therefore, there is a need for a cross-sectional study in Law undergraduate programs of legal issues related to homoaffectivity, since these issues are a social reality linked to the most diverse areas of legal science. The tools made available by Resolution CES/CNE 5/2018 enable the learning of issues related to sexual minorities, through the dynamic connection of these issues with the various disciplines of law education. The methodological perspective chosen is based on complex thinking. Systemic results are prevalent here, privileging the inter and transdisciplinarity of the branches of Law and other areas of human knowledge. Based on doctrine, jurisprudence, and the parliamentary system, the work reveals the transdisciplinary function of Homoaffective Rights in undergraduate law degrees. As a cross-cutting theme, this approach can contribute to the formation of necessary skills for the academic, professional, and family life of contemporary jurists, strengthening tolerance and respect in society.
\end{abstract}

KEYWORDS: Resolution CES/CNE 5/2018. Higher legal education. Homoaffective Rights. Sexual and gender diversity. Transdisciplinarity. 


\section{INTRODUÇÃO}

O assunto que move o presente artigo reside em verificar a viabilidade da inserção do Direito Homoafetivo, da Diversidade Sexual e de Gênero como tema transversal no novo ensino jurídico superior, nos termos do sistema jurídico vigente e das novas diretrizes emanadas pela Resolução CES/CNE ${ }^{1}$ 5/2018. Em sendo assim, aborda-se em qual medida essa viabilidade do ensino transversal do Direito Homoafetivo contribui no desenvolvimento de competências necessárias à vida acadêmica, profissional e familiar do jurista contemporâneo.

A necessidade da produção do presente trabalho é justificável pela possibilidade da abertura de horizontes que o Direito Homoafetivo pode promover aos graduandos em Direito, no que se refere a novos conhecimentos acerca da realidade em que se vive atualmente e das questões emergentes relacionadas à população LGBTI+ (Lésbicas, Gays, Bissexuais, Transgêneros, Intersexuais e demais). Os alunos do Direito, em virtude da área que escolheram seguir, precisam ter um manejo adequado com as mais variadas pessoas, independentemente de sua sexualidade ou de qualquer outro atributo. Uma visão, a mais ampla possível e também crítica, acerca do mundo em volta irá fazer a diferença no desenvolvimento dos juristas contemporâneos e na construção de uma sociedade mais tolerante e baseada no respeito.

E o Direito Homoafetivo, da Diversidade Sexual e de Gênero pode promover tal visão na medida em que trata de temas relacionais às pessoas consideradas minorias sexuais. Essas pessoas existem, fazem parte do meio social e a sua sexualidade tem influência dentro do sistema jurídico contemporâneo, tanto nacional quanto internacionalmente. Assim, este artigo objetiva traçar uma visão geral acerca dos conceitos relacionados a essa população. Também, objetiva-se abordar as normas que embasam o ensino e a pesquisa no sistema educacional superior em nível de graduação em Direito. Daí verifica-se uma conexão entre a normatização vigente, com atenção para a nova Resolução CES/CNE $5 / 2018$, e a viabilidade do ensino do Direito Homoafetivo como tema transversal nos cursos de Direito.

A pesquisa baseia-se na análise da doutrina especializada em Direito Homoafetivo, da Diversidade Sexual e de Gênero, na verificação da normatização que orienta o ensino jurídico superior no Brasil, bem como nas diversas jurisprudências, em especial, do

\footnotetext{
${ }^{1}$ CES/CNE - Câmara de Educação Superior/Conselho Nacional de Educação.
} 
Supremo Tribunal Federal, acerca das consequências jurídicas da homotransafetividade. A partir dessa matéria-prima e das informações coletadas, trabalha-se dentro de uma perspectiva metodológica fundada no pensamento complexo e com prevalência de resultados sistêmicos, privilegiando a inter e a transdisciplinaridade dos ramos do Direito e das demais áreas do conhecimento humano.

\section{ENTENDENDO HOMOAFETIVIDADE, DIVERSIDADE SEXUAL E IDENTIDADE DE GÊNERO}

Inicia-se, para melhor entendimento dos conceitos a serem utilizados nestes escritos, fazendo algumas breves explicações. O termo homoafetivo foi inicialmente cunhado por Maria Berenice Dias, escritora, advogada e desembargadora aposentada, para designar as uniões e os relacionamentos baseados no afeto romântico entre pessoas do mesmo sexo (DIAS, 2017). Hoje em dia o termo homoafetivo expandiu seu significado, vinculando-se a todas as situações afetivas em que estejam presentes um gay individualmente ou casais do mesmo sexo, como, por exemplo, no caso de adoção homoafetiva. Assim é que o termo homoafetivo foi largamente utilizado na histórica decisão do Supremo Tribunal Federal (STF) sobre a constitucionalidade das uniões entre pessoas do mesmo sexo, em 2011 (BRASIL, 2011).

Pondere-se que o termo homoafetivo desconstrói o preconceito social baseado na conjectura de que pessoas do mesmo sexo somente firmavam seus relacionamentos apenas no desejo erótico sempre desprovido do amor sublime que somente seria atributo dos casais formados por pessoas de sexos opostos (VECCHIATTI, 2012).

O grupo de pessoas consideradas diversidade sexual e de gênero possui denominação muito conhecida atualmente, qual seja LGBTI+. A sigla LGBTI+, que não raro possui variações (LGBT, por exemplo), foi criada para unir as diversas manifestações de sexualidade existentes, para além do modelo padrão bivalente homem/mulher, masculino/feminino, tais como Lésbicas, Gays, Bissexuais, Transgêneros, Intersexos, Assexuais, Queers e inúmeros outros. Destaque deve ser dado para a contribuição da teoria queer ${ }^{2}$ que colabora com a desconstrução do sujeito limitado e apresenta

${ }^{2}$ Teoria Queer"(queer theory) - postura intelectual nascida do pós-estruturalismo, que ganhou força a partir do final da década de 1980 nas universidades americanas e de lá se difundiu para o resto do mundo. A Teoria Queer representa antes de tudo um posicionamento claro contra toda as classificações e hierarquias sexuais e de gênero. Ela está fundada em um conjunto de ideias e 
possibilidade de alteração da noção de instabilidade e indeterminação das identidades sexuais.

Sugere Silva (2019) que "a cortina de fumaça que é feita na ideologia de gênero 3 também gera uma errônea ideia de que quem a combate estaria a combater o homossexualismo". Entretanto, observa-se uma desconexão nas afirmações expostas pela autora. Explica-se. Inicialmente, vale mencionar que desde 1993 a Organização Mundial da Saúde (OMS) não considera o relacionamento amoroso e/ou sexual entre pessoas do mesmo sexo algo contrário à higidez mental ou comprometedor da saúde dessas pessoas (VECCHIATTI, 2012). Daí, totalmente descabida a utilização da palavra "homossexualismo", em que o "ismo" sugere uma conotação de doença. Extremamente impróprio o uso desse termo, por estar desconexo com a realidade social atual e inclusive com as diretrizes da medicina, da psicologia e do sistema jurídico da civilização contemporânea.

Registre-se, também, que a expressão "ideologia de gênero" se trata de uma "expressão cunhada por fundamentalistas religiosos para deturpar o debate acerca de equidade e identidade de gênero - como se essa agenda representasse a abolição da diferença biológica entre os sexos". Engendra, assim, tal expressão "enfraquecer a luta por direitos das pessoas transexuais e das mulheres em geral" (SANTOS, 2016).

Esclareça-se que orientação sexual e identidade de gênero são conceitos diferentes. A orientação sexual está relacionada, como o próprio nome revela, ao direcionamento do desejo e/ou afeto sexual que atrai uma pessoa. Assim, quando o desejo e/ou afeto ocorrer entre pessoas do mesmo sexo, a pessoa é considerada homossexual ou homoafetiva. Quando o afeto e/ou desejo sexual está orientado para o sexo oposto, tem-se que a pessoa é heterossexual ou heteroafetiva. Mais ainda, se o desejo sexual ocorre indistintamente por ambos os sexos, a pessoa é denominada de bissexual ou biafetiva. Por seu turno, os assexuais são aquelas pessoas que não sentem atração por nenhum dos sexos. Vale mencionar que se pode encontrar diversas outras modalidades de orientação sexual.

conceitos construídos a partir da ideia central de que as identidades, sexuais e de gênero, não são instituições fixas e nem determinam quem nós somos. [...]" (LANZ, 2017, p. 422-423)

3 "Surgimento. O termo "Ideologia de gênero" aparece pela primeira vez em 1998, em um documento eclesiástico, em uma nota da Conferência Episcopal do Peru, intitulada "A ideologia de gênero: seus perigos e alcances". Isso é demonstrado no artigo "Ideologia de gênero": a gênese de uma categoria política reacionária - ou: a promoção dos direitos humanos se tornou uma "ameaça à família natural?", de Rogério Diniz Junqueira, da Unb. [...] 'Kit gay. Em 2011, produção de um material do Projeto Escola Sem Homofobia causa polêmica e é chamado de 'kit gay'. A política previa vídeos e material para o professor, com foco no ensino médio. Após críticas e ataques, iniciativa é engavetada. Fernando Haddad (PT) era ministro da Educação. [...]" (SALDAÑA, 2018) 
Passando agora para a identidade de gênero, retruca Silva (2016) que o indivíduo, do ponto de vista da espécie, é macho ou fêmea; sob o ponto de vista biológico, homem ou mulher; e, quanto ao aspecto social, masculino ou feminino, de modo que casos como de "disforia de gênero", em que a pessoa sofre transtorno psicológico caracterizado por "sentimento persistente de inadequação ao gênero imposto no nascimento", que exigem cuidados especiais, não são a regra.

Desse modo, há uma concepção que, de maneira simplista, diz que o gênero é a identidade criada para enquadrar, sob um viés reducionista, uma pessoa como homem macho masculino ou mulher fêmea feminino. Sabe-se que normalmente se é induzido ao entendimento de que é pertencente ao gênero masculino aquela pessoa que nasceu com genitália do tipo pênis, e a quem são atribuídas específicas funções comportamentais, tais como, utilização predominante de vestuário da cor azul, que brincou com carrinho quando criança, que gosta de mulher, dentre outras.

O gênero feminino, por seu turno, foi condicionado à mulher, e se estabelece pelo nascimento com a genitália do tipo vagina, e a quem são fixadas funções comportamentais específicas, tipo, utilização de vestimenta predominantemente da cor rosa e imposição de que essa pessoa quando criança deva brincar com bonecas e miniutensílios domésticos, quando adulta deve gostar de homem, dentre outras.

Nessa discussão acerca do gênero é que se pode dizer que a pessoa é considerada cisgênero quando se identificar com o gênero que lhe foi atribuído no nascimento, ou seja, homem masculino e mulher feminina. Cisgênero tem o prefixo "cis", originário do latim, e significa "deste lado".

Já o transgênero é a denominação internacional que genericamente engloba os transexuais e as travestis. O transexual é aquela pessoa cuja conformação psicomorfofisiológica não se ajustam ao enquadramento social, promovido quando do nascimento, para o gênero masculino ou feminino. Ou seja, não há a exata conexão entre o sexo biológico macho e fêmea e o gênero masculino e feminino condicionados socialmente. Daí o prefixo "trans", originado do latim, significar "além de". Portanto, o homem transgênero, ou transhomem, é aquela pessoa que possui características corporais de nascimento vinculadas a uma fêmea, mas que tem profundo sentimento de pertencimento ao gênero masculino. Por outro lado, a mulher transgênero, ou transmulher, é a pessoa que ao nascer foi identificada socialmente como macho, mas que se autopercebe como do gênero feminino. 
Nessa modalidade de gênero considerada transgênero, tem-se também as conhecidas pessoas denominadas travestis. A travesti, apesar de viver integralmente como mulher no dia a dia, não está em conflito com os seus genitais de macho que, ao contrário, são parte efetiva do seu desempenho como pessoa como outra qualquer (LANZ, 2017).

Por seu turno, Intersexo ou, na ultrapassada linguagem anterior, hermafrodita, consiste em uma pessoa que reúne as características dos sexos macho e fêmea. Parafraseando Rodrigo da Cunha Pereira, discorre-se que intersexual é a pessoa que nasceu fisicamente entre, daí o prefixo "inter", o sexo masculino e o feminino, tendo parcial ou completamente desenvolvidos ambos os órgãos sexuais, ou um predominando sobre o outro. A intersexualidade pode se manifestar tanto no cariótipo, exame de cromossomos, quanto no fenótipo, características externas da pessoa (DIAS; BARRETTO, 2018).

Vale lembrar que as considerações expostas anteriormente foram apenas formuladas para uma melhor compreensão dos conceitos relacionados à sexualidade, não sendo estáticas, podendo serem flexibilizadas e ampliadas, tendo em vista a pluralidade natural dessa característica humana.

Na sequência, a fim de dar continuidade ao desenvolvimento das ideias enfatizadas por estes escritos, estabelecer-se-á um panorama acerca do conjunto legal que orienta o ensino jurídico brasileiro, com ênfase no ensino superior da graduação em Direito.

\section{DISPOSIÇÕES NORMATIVAS ACERCA DO ENSINO JURÍDICO NO BRASIL}

Especificamente em relação à educação de nível superior, determina a atual Constituição Federal de 1988 que é dever do Estado garantir o acesso aos níveis mais elevados do ensino, da pesquisa e da criação artística, segundo a capacidade de cada um (art. 208, V, CF/88). Estabelece que "as universidades gozam de autonomia didáticocientífica, administrativa e de gestão financeira e patrimonial, e obedecerão ao princípio de indissociabilidade entre ensino, pesquisa e extensão" (art. 207, CF/88) (BRASIL, [1988]).

Disso decorre que, no âmbito infraconstitucional também se deve prestigiar de forma inafastável a educação, uma vez que o sistema normativo brasileiro deve estar totalmente em conformidade com os princípios e regras constitucionais. Assim sendo, a Lei 9.394/1996, conhecida por Lei de Diretrizes e Bases da Educação Nacional (LDB), como a 
própria designação já confirma de pronto, fornece a direção a ser seguida pela educação brasileira (BRASIL, [1996]).

A LDB deixa claro no $\S 2^{\circ}$ do art. $1^{\circ}$ que a educação escolar deverá vincular-se ao mundo do trabalho e à prática social. Mais ainda, o art. $2^{\circ}$ reforça a promoção do ensino inspirada nos princípios de liberdade e nos ideais de solidariedade humana, tendo por finalidade o pleno desenvolvimento do educando, seu preparo para o exercício da cidadania e sua qualificação para o trabalho. $O$ art. $3^{\circ}$ da LDB determina que são princípios básicos do ensino: a liberdade de aprender, ensinar, pesquisar e divulgar a cultura, o pensamento, a arte e o saber; o pluralismo de ideias e de concepções pedagógicas; o respeito à liberdade e apreço à tolerância; a vinculação entre a educação escolar, o trabalho e as práticas sociais; e a consideração com a diversidade étnico-racial.

Dentro da conjuntura criada para o ensino, identifica-se que a Lei de Diretrizes e Bases também aborda a efetivação da Educação Superior. Nos termos da LDB, entendese que a Educação Superior possui importante papel no direcionamento do ensino e pesquisa em prol dos conhecimentos sobre diversidade sexual e de gênero. Tanto é assim que o art. 43 dessa Lei expõe que a educação superior tem por finalidade desenvolver o entendimento da pessoa humana e do meio em que vive.

De forma articulada com a LDB, a Lei 13.005/2014 institui o Plano Nacional de Educação (PNE) 2014-2024, com vigência de 10 (dez) anos. Resolve o art. $2^{\circ}$ do PNE estabelecer como suas diretrizes: a superação das desigualdades educacionais, com ênfase na promoção da cidadania e na erradicação de todas as formas de discriminação, e a promoção dos princípios do respeito aos direitos humanos, à diversidade e à sustentabilidade socioambiental (BRASIL, [2014]).

Direcionando-se especificamente para o campo do ensino jurídico superior, o Parecer 635/2018, da Câmara de Educação Superior (CES) do Conselho Nacional de Educação (CNE), trata da revisão das diretrizes curriculares nacionais do curso de graduação em Direito (BRASIL, [2018a]). Esse parecer supre a expectativa de parte da comunidade acadêmica e de setores que representam a atuação profissional da área, no sentido de ajustar a estrutura desses cursos ao atual momento histórico.

Portanto, esse parecer é documento que contém um viés favorável ao ensino do Direito Homoafetivo e da Diversidade Sexual e de Gênero. Isso porque as revisões mencionadas no Parecer 635/2018 reafirmam que o curso de graduação em Direito deverá assegurar, no perfil do graduando, sólida formação geral, humanística e axiológica, capacidade de análise, interpretação e valorização dos fenômenos jurídicos e sociais, em 
consonância com uma postura reflexiva e de visão crítica que fomente à capacidade e à aptidão para a aprendizagem autônoma e dinâmica, indispensável ao exercício da Ciência do Direito, da prestação da justiça e do desenvolvimento da cidadania (BRASIL, [2018a]).

Ensinar o Direito não significa simplesmente reproduzir os dogmas, as teorias, a letra da lei. Ao contrário, a função principal do professor é problematizar a realidade que o cerca, bem como seus alunos, para, calcado nesta premissa, apontar caminhos para a construção de um Direito promotor de verdade e justiça (CARVALHO, 2011).

O Parecer CES/CNE 635/2018 aponta, como questão mais urgente, a averiguação da atualidade dos currículos, bem como a articulação interdisciplinar e as diversas possibilidades curriculares, e sua concatenação com pesquisa e extensão (BRASIL, [2018a]).

Dito Parecer justifica que o curso de Direito, antes de ser autorizado pelo Ministério da Educação (MEC), depende da manifestação prévia da Ordem dos Advogados do Brasil (OAB) (BRASIL, [2018a]). Assim é que, o art. 41 do Decreto 9.235/2017 estabelece que a oferta de cursos de graduação em Direito necessita de prévia manifestação do Conselho Federal da OAB (BRASIL, 2017).

Assim sendo, o Regulamento Geral, previsto no art. 83 da Lei 8.906/1994 (Estatuto da Ordem dos Advogados do Brasil), afirma que compete à Comissão Nacional de Educação Jurídica do Conselho Federal da OAB opinar previamente nos pedidos para criação, reconhecimento e credenciamento dos cursos jurídicos (BRASIL, 2020b). Há também o Provimento 164/2015 que criou o Plano Nacional de Valorização da Mulher Advogada. $\mathrm{O}$ art. $2^{\circ}$ desse Provimento define que o fortalecimento dos direitos humanos da mulher, terá como diretriz a educação jurídica (BRASIL, 2020a). Além mais, o Conselho Federal e as Seccionais da Ordem dos Advogados do Brasil contam com Comissões Especiais de Direito Homoafetivo, da Diversidade Sexual e de Gênero, que possuem influência importante no direcionamento da forma como a OAB opina nos pedidos de criação, reconhecimento, credenciamento e até mesmo na qualidade dos cursos jurídicos brasileiros.

No Parecer CES/CNE 635/2018, o item 5 aborda as diretrizes curriculares nacionais do curso de graduação em Direito. Mais especificamente, o subitem 5.1 se concentra no projeto pedagógico. Estabelece que esse projeto deve contemplar as formas de tratamento transversal dos conteúdos exigidos nas diretrizes nacionais, tais como, a educação em direitos humanos; a educação em políticas de gênero; a educação das relações étnicoraciais (BRASIL, [2018a]), disso decorrendo, conforme se entende, as questões LGBTI+. 
O referido Parecer conta também com o item 5.2 que cuida do perfil do egresso, tanto de modo geral, como em relação a competências e habilidades. Assim esclarece que o curso de graduação em Direito deverá assegurar, no perfil do graduando, sólida formação geral, humanística, aliada a uma postura reflexiva e de visão crítica (BRASIL, [2018a]).

O item 5.3 do Parecer CES/CNE 635/2018 expõe a organização curricular dos cursos de Direitos. Tendo em vista a diversificação curricular, as Instituições de Ensino Superior (IES) poderão introduzir no Projeto Pedagógico de Curso (PPC) conteúdos e componentes curriculares, visando articular novas competências e saberes necessários aos novos desafios que se apresentem ao mundo do Direito (BRASIL, [2018a]), tais como as demandas trazidas pelo Direito Homoafetivo.

Como consequência das ponderações inseridas no Parecer ora em análise, foi expedida a recente Resolução 5/2018, também de lavra do Conselho Nacional de Educação (CNE) / Câmara de Educação Superior (CES), instituindo as diretrizes curriculares nacionais do curso de graduação em Direito, bacharelado, a serem observadas pelas Instituições de Educação Superior (IES) (BRASIL, [2018b]).

$\mathrm{O} \S 1^{\circ}$ do art. $2^{\circ}$ da Resolução CES/CNE 5/2018 dispõe que o Projeto Pedagógico do Curso de Direito (PPC) abrangerá, dentre outros, os elementos estruturais relacionados à realização de interdisciplinaridade. Em continuação, o $\S 4^{\circ}$ do art. $2^{\circ}$ da Resolução CES/CNE 5/2018 institui que o Projeto Pedagógico de Curso (PPC) deve prever ainda as formas de tratamento transversal dos conteúdos exigidos em diretrizes nacionais específicas, tais como as políticas de educação em direitos humanos, de educação das relações étnico-raciais, abrindo espaço, desse modo, para a educação em políticas relacionadas à homoafetividade e à diversidade sexual e de gênero, como será desenvolvido a seguir.

\section{ENSINO JURÍDICO DO DIREITO HOMOAFETIVO, DA DIVERSIDADE SEXUAL E DE GÊNERO COMO TEMA TRANSVERSAL NO CURSO DE GRADUAÇÃO EM DIREITO}

A história do pensamento é um desenrolar constante da evolução de conceitos, teorias, modos de pensar, de agir e de fazer. Disso decorre que a existência da Ciência do Direito deve se moldar ao processo de transformação social. Nessa perspectiva, o pensamento complexo, por meio de suas categorias e princípios basilares, surge como uma 
alternativa para repensar a realidade e reformular a ciência. Está inserido necessariamente nesse cenário de superação sistêmica, o estudo e aplicação do Direito Homoafetivo e da Diversidade Sexual e de Gênero.

Nos termos do pensamento clássico, cuja lógica é linear e formal, não existe absolutamente coisa alguma entre, através e além das disciplinas, tendo em vista que segundo o paradigma simplista, só existe um nível de realidade. No entanto, a interdisciplinaridade cuida da transferência de métodos de uma disciplina para outra. Em adição, a transdisciplinaridade se interessa pela dinâmica gerada pela ação dos vários níveis de realidade ao mesmo tempo, o que a faz estar relacionada com a ciência pósmoderna e a ideia de diálogos dos saberes.

Nesse sentido, Pepê e Hidalgo (2013) propõem um ensino jurídico dogmática e epistemologicamente bem construído, por meio da utilização de tarefa de prazer, de resgate da intersubjetividade, da transdisciplinaridade e da projeção de sentidos autênticos no mundo. Faria (2014) aponta que a opção por um ensino participativo que acredita e se desenvolve com base no protagonismo do aluno na construção do conhecimento pelo enfrentamento de problemas diversos prestigia uma visão do direito mais complexa e articulada com um universo múltiplo de atores e questões.

Então, por que e para que estudar Direito Homoafetivo e da Diversidade Sexual e de Gênero, inserido como tema transversal nas diversas disciplinas do curso de graduação em Direito? A resposta está no fato de que, ao se atentar para a realidade social, percebe-se a pluralidade de características surgidas em virtude da natureza singular de cada ser humano, em especial, da natureza diversificada da sexualidade das pessoas, enquanto ser único e complexo. E essa sexualidade atrelada de forma inseparável do próprio modo de ser do indivíduo, atributo intrínseco da personalidade de cada um, por óbvio, reflete-se sobremaneira nas relações sociais e, por conseguinte, finda por produzir consequências as mais variadas possíveis no mundo jurídico, em suas mais distintas especialidades.

Nota-se, pois, que há toda uma construção jurídica baseada nos direitos e obrigações dos LGBTI+, que, inclusive, alcança as mais diversas ramificações do Direito e ciências afins, interagindo com o Direito Público e o Direito Privado, o Direito Constitucional, o Direito Civil, o Direito Penal, o Direito Processual, a Sociologia Jurídica, a Filosofia do Direito, a Teoria do Estado, dentre outras. Mais ainda, o Direito Homoafetivo também é temática em âmbito internacional, sendo preocupação das mais diversas organizações multilaterais. Assim, necessário o estudo do Direito Homoafetivo dentro das disciplinas do 
currículo básico e das disciplinas complementares na graduação em Direito, a fim de proporcionar uma ampla formação jurídica e humana aos futuros juristas. Senão vejamos.

A escola é outro espaço na sociedade onde a homossexualidade manifestase, seja nos corpos dos sujeitos ou em materiais educativos. Observa-se no Brasil um esforço para tornar a escola um espaço para a discussão de questões de sexualidade e gênero, bem como de reconhecimento da identidade de gênero (DO ESPIRITO SANTO, 2017, p. 88).

É inconcebível falar em sexualidade e Direitos LGBT sem se ater ao Princípio da Dignidade da Pessoa Humana. Esse princípio se revela deveras importante para a vida em sociedade (inc. III, art. 1º, CF/88) (BRASIL, [1988]). Aqui já se pode conceber a discussão do Direito Homoafetivo de forma transdisciplinar com disciplinas como Direito Constitucional, Teoria Geral do Estado e Direito Administrativo.

Na mesma direção da Carta Maior brasileira, o Supremo Tribunal Federal (STF) se detém acerca do direito à sexualidade. Diz a Suprema Corte que a liberdade para dispor da própria sexualidade está inserida na categoria dos direitos fundamentais do indivíduo, é expressão da autonomia de vontade, insere-se no direito à intimidade e à vida privada e, portanto, situa-se no rol das cláusulas pétreas (BRASIL, [2011]).

Por isso, como exemplo, conforme o gabinete federal antidiscriminação da Alemanha (ALEMANHA, 2017), a desvalorização e a discriminação de pessoas com base na orientação sexual ou identidade de gênero violam os valores fundamentais de uma constituição democrática, pautada nos direitos humanos, assim como valores éticos e morais básicos, sejam eles humanistas ou derivados da religião. A igualdade determina assim decisivamente a qualidade ética e democrática de uma sociedade.

[...] Abwertung und Diskriminierung von Menschen aufgrund von Merkmalen wie der sexuellen Orientierung oder der Geschlechtsidentität verstoßen gegen die fundamentalen Grundwerte einer demokratischen Verfasstheit, die das Grundgesetz und die Menschenrechte vorgeben, und gegen ethische und moralische Grundwerte, seien sie humanistisch oder religiös abgeleitet. Das Ausmaß realisierter Gleichwertigkeit bestimmt also ganz entscheidend über die ethische und demokratische Qualität einer Gesellschaft (in Anlehnung an Heitmeyer, 2002). (ALEMANHA, 2017).

Continuando, o STF abordou o tema da adoção homotransafetiva. Segundo a Corte Constitucional, se as uniões homoafetivas já são reconhecidas como entidade familiar, em virtude de vínculo afetivo, não há razão para limitar a adoção, criando obstáculos onde a lei não prevê (Min. Cármen Lúcia, RE 846102 / PR, julgado 5.3.2015) (BRASIL, 2015). A disciplina relacionada ao Estatuto da Criança e do Adolescente seria acrescida desses temas do Direito Homoafetivo e de Gênero. 
É válido fazer referência à decisão conjunta do STF na ADO 26-PPS, de Relatoria do Ministro Celso de Mello, e do MI 4733-ABGLT, de Relatoria do Ministro Edson Fachin, sobre a criminalização da homotransfobia (BRASIL, 2019). Aqui, sem dúvidas, o Direito Homoafetivo estaria tratando de temas também intrínsecos às disciplinas de Direito Penal e Processual Penal.

Além das mencionadas, diversas outras situações amparadas juridicamente estão vinculadas à diversidade sexual e de gênero. Evidencie-se que tais questões perpassam os mais variados ramos do Direito. Nesse sentido, entende-se que a nova Resolução CNE/CES 5/2018 permite o ensino transversal do Direito Homoafetivo em todo o ensino jurídico superior na graduação em Direito. Senão vejamos.

Orientada pelos ditames constitucionais, a Resolução CNE/CES 5/2018 decide em seu art. $3^{\circ}$ que o curso de graduação em Direito deverá assegurar, no perfil do graduando, sólida formação humanística. Deve ainda o curso de graduação desenvolver no aluno a capacidade de argumentação, interpretação e valorização dos fenômenos jurídicos e sociais, aliado a uma postura reflexiva e de visão crítica (BRASIL, [2018b]).

O art. $4^{\circ}$ dessa Resolução prescreve que o curso de graduação em Direito deverá possibilitar a formação profissional que revele, pelo menos, as competências cognitivas, instrumentais e interpessoais que capacitem o graduando a: aceitar a diversidade e o pluralismo cultural; desenvolver a capacidade de trabalhar em grupos formados por profissionais do Direito ou de caráter interdisciplinar; e apreender conceitos deontológicoprofissionais e desenvolver perspectivas transversais sobre direitos humanos (BRASIL, [2018b]).

Por seu turno, o art. $5^{\circ}$ da Resolução CNE/CES 5/2018 estabelece que o curso de graduação em Direito, priorizando a interdisciplinaridade e a articulação de saberes, deverá incluir no Projeto Pedagógico do Curso (PPC) conteúdos e atividades de formação geral em diálogo com as demais expressões do conhecimento filosófico e humanístico e das ciências sociais, abrangendo estudos que envolvam saberes de outras áreas formativas (BRASIL, [2018b]).

Nesse cenário de fortalecimento do ensino jurídico LGBTI+, é que o Projeto de Estatuto da Diversidade Sexual e de Gênero (PLS 134/2018 - PEDSG), em tramitação no Senado Federal, iniciou-se da unificação das inúmeras ideias sugeridas pelas Comissões da Diversidade Sexual e Gênero da Ordem dos Advogados de todas as regiões do Brasil, pela Comissão de Direito Homoafetivo do Instituto Brasileiro de Direito de Família (IBDFAM) e pelos movimentos sociais. 
O Projeto do Estatuto da Diversidade Sexual e Gênero possui todo o Capítulo X tratando sobre o direito à educação, dos arts. 56 a 61. Assim é que o art. 56 do PEDSG determina que os estabelecimentos públicos e privados de ensino têm o dever de promover a liberdade, a tolerância, a igualdade, a diversidade e o respeito entre as pessoas, independentemente de sua orientação sexual ou identidade de gênero. No caso do art. 58, o PEDSG firma que os profissionais da educação têm a obrigação de abordar os temas relativos à sexualidade (BRASIL, [2018c]).

Fundamentada está, portanto, por meio das determinações emanadas do sistema jurídico brasileiro, em especial, da Resolução CNE/CES 5/2018, a viabilidade, importância e necessidade do ensino inter e transdisciplinar do Direito Homoafetivo, da Diversidade Sexual e de Gênero, como tema transversal nas diversas disciplinas do currículo do curso de graduação em Direito (BRASIL, [2018c]). Dita inserção traz benefícios para os acadêmicos de Direito, na medida em que fornece os conhecimentos imprescindíveis à vida educacional, profissional e familiar desses graduandos, bem como promove o fortalecimento da tolerância e do respeito no meio social.

\section{CONSIDERAÇÕES FINAIS}

A pesquisa retratou a relevância e a viabilidade do ensino jurídico do Direito Homoafetivo, da Diversidade Sexual e de Gênero, como tema transversal a ser discutido em todas as disciplinas curriculares do curso de graduação em Direito nas Instituições de Ensino Superior, tendo como suporte as novas diretrizes curriculares introduzidas pela Resolução CES/CNE 5/2018.

É evidente que a homoafetividade, a diversidade sexual e a identidade de gênero são características resultantes da forma plural de se manifestar da sexualidade humana e possuem reflexos no sistema jurídico normatizador da vida em sociedade, independentemente do ramo do Direito. Para verificar isso, analisou-se, por exemplo, inúmeras decisões prolatadas pelo Poder Judiciário, em especial, pelo Supremo Tribunal Federal. Atentou-se para as discussões sobre o tema na doutrina, bem como as iniciativas legislativas e educacionais, as ações na administração pública e a proatividade das organizações não governamentais.

Assim sendo, é imprescindível o estudo transversal na graduação em Direito das questões jurídicas relacionadas à homoafetividade, uma vez que essas questões são 
realidade social vinculada às mais diversas áreas de atuação da ciência jurídica. É evidente a relevância do papel do Direito Homoafetivo na consolidação do conhecimento jurídico relacionado às garantias e direitos dos cidadãos LGBTI+, e, por consequência, de todos os cidadãos brasileiros. Mesmo porque, os conhecimentos atinentes ao Direito Homoafetivo estão em dinâmica interseção com os diversos outros ramos do Direito e, além mais, com as diversas áreas do labor humano, de forma complexa e sistemática.

Necessário se faz o incessante fortalecimento da ciência jurídica em direção ao seu objetivo maior: a pessoa humana. Isso permite que, por exemplo, ramos do Direito como o Homoafetivo, da Diversidade Sexual e de Gênero e o Ambiental possam se consolidar no mundo contemporâneo e se fundir com outras disciplinas jurídicas em prol da justiça para todos na sociedade.

Uma visão de educação e pesquisa jurídica renovada está estabelecida nas atuais diretrizes curriculares assumidas pela Resolução CES/CNE 5/2018. Esse normativo traz inúmeras ferramentas propulsoras do ensino-aprendizagem na graduação em Direito. Isso possibilita que os formandos, através do ensino, da pesquisa e da extensão, se percebam pessoas autônomas e, ao mesmo tempo, participantes de uma sociedade formada por interações complexas entre indivíduos os mais diversos possíveis.

Essa Resolução promove no futuro jurista uma postura ativa, mesmo diante de todas as dificuldades impostas pela realidade. Dita postura ensejará a busca de soluções críticas e humanas para as inúmeras possibilidades que os juristas do futuro terão que vivenciar, inclusive no que diz respeito às questões relacionadas à diversidade sexual e de gênero. Portanto, as novas práticas educacionais mencionadas colaboram, assim, para o fortalecimento da tolerância e do respeito no processo de convivência em sociedade.

\section{REFERÊNCIAS}

ALEMANHA. Antidiskriminierungsstelle des Bundes. Einstellungen gegenüber lesbischen, schwulen und bisexuellen Menschen in Deutschland: Ergebnisse einer bevölkerungsrepräsentativen Umfrage. Berlin: Antidiskriminierungsstelle des Bundes, 2017. Disponível em:

https://www.antidiskriminierungsstelle.de/SharedDocs/Downloads/DE/publikationen/Umfra gen/Umfrage Einstellungen geg lesb schwulen und bisex Menschen DE.pdf? blob= publicationFile\&v=2 Acesso em: 18 mar. 2020.

BRASIL. Conselho Federal da Ordem dos Advogados do Brasil. Provimento n. 164/2015. In: Estatuto da Advocacia e da OAB e Legislação Complementar. Versão eletrônica atualizada. Brasília: OAB, Conselho Federal, 2020a. Disponível em: 
https://www.oab.org.br/publicacoes/AbrirPDF?Livrold=0000002837 Acesso em: 16 mar. 2020. p. 209-211.

BRASIL. Conselho Federal da Ordem dos Advogados do Brasil. Regulamento Geral do Estatuto da Advocacia e da OAB. In: Estatuto da Advocacia e da OAB e Legislação Complementar. Versão eletrônica atualizada. Brasília: OAB, Conselho Federal, $2020 \mathrm{~b}$. Disponível em: https://www.oab.org.br/publicacoes/AbrirPDF?Livrold=0000002837 Acesso em: 16 mar. 2020. p. 33-82.

BRASIL. Ministério da Educação (MEC). Parecer CNE-CES n. 635/2018. Revisão das Diretrizes Curriculares Nacionais do curso de graduação em Direito. Brasília: Ministério da Educação, [2018a]. Aprovado em 04/10/2018. Parecer homologado: Portaria $\mathrm{n}^{\circ} 1.351$, publicada no Diário Oficial da União (D.O.U.) de 17/12/2018, s. 1, p. 34. Disponível em: http://portal.mec.gov.br/docman/outubro-2018-pdf-1/100131-pces635-18/file Acesso em: 27 ago. 2019.

BRASIL. Ministério da Educação (MEC). Plano Nacional de Educação - Lei $\mathbf{n}$. 13.005/2014. Brasília, DF: Ministério da Educação, [2014]. Disponível em: http://pne.mec.gov.br/18-planos-subnacionais-de-educacao/543-plano-nacional-deeducacao-lei-n-13-005-2014 Acesso em: 6 jun. 2019.

BRASIL. Ministério da Educação (MEC). Resolução n. 5, de 17 de dezembro de 2018. Institui as Diretrizes Curriculares Nacionais do Curso de Graduação em Direito e dá outras providências. Brasília: Ministério da Educação, [2018b]. Câmara de Educação Superior (CES). Conselho Nacional de Educação (CNE). Diário Oficial da União (D.O.U.) n. 242,18/12/2018, s. 1, p. 122. Brasília: Associação Brasileira de Mantenedoras de Ensino Superior (ABMES), [2018]. Disponível em: http://www.abmes.org.br/arquivos/legislacoes/Resol \%20CNEn5.pdf Acesso em: 5 jun. 2019.

BRASIL. Presidência da República. Constituição da República Federativa do Brasil de 1988. Brasília: Presidência da República, [1988]. Disponível em: http://www.planalto.gov.br/ccivil 03/constituicao/constituicaocompilado.htm Acesso em: 6 jun. 2019.

BRASIL. Presidência da República. Decreto n. 9.235/2017. Brasília: Presidência da República, 2017. Disponível em: http://www.in.gov.br/web/dou/-/decreto-n-9-235-de-15-dedezembro-de-2017-1101286-

1101286\#: :text=D\%20E\%20C\%20R\%20E\%20T\%20A\%20\%3A,no\%20sistema\%20feder al\%20de\%20ensino Acesso em: 16 mar. 2020.

BRASIL. Presidência da República. Lei n. 9.394, de 20 de dezembro de 1996. Estabelece as diretrizes e bases da educação nacional. Brasília: Presidência da República, [1996]. Disponível em: http://www.planalto. gov.br/ccivil 03/leis/l9394.htm Acesso em: 6 jun. 2019.

BRASIL. Senado Federal. Projeto de Lei do Senado n. 134, de 2018. Institui o Estatuto da Diversidade Sexual e de Gênero. Autoria: Comissão de Direitos Humanos e Legislação Participativa. Brasília: Senado Federal, [2018c]. Disponível em:

https://legis.senado.leg.br/sdleg- 
getter/documento?dm=7651070\&ts=1545410725371\&disposition=inline Acesso em: 10 abr. 2019.

BRASIL. Supremo Tribunal Federal (STF). Ação Direta de Inconstitucionalidade por Omissão 26 Distrito Federal. Ementa: Ação Direta de Inconstitucionalidade por Omissão - exposição e sujeição dos homossexuais, transgêneros e demais integrantes da comunidade LGBTI+ a graves ofensas aos seus direitos fundamentais em decorrência de superação irrazoável do lapso temporal necessário à implementação dos Mandamentos Constitucionais de criminalização instituídos pelo Texto Constitucional (CF, art. $5^{\circ}$, incisos XLI e XLII) [...]. Relator Min. Celso de Mello. Julgamento em 13 jun. 2019. Disponível em: http://www.stf.jus.br/arquivo/cms/noticiaNoticiaStf/anexo/ADO26ementaassinada.pdf

Acesso em: 24 set. 2019.

BRASIL. Supremo Tribunal Federal (STF). Arguição de Descumprimento de Preceito Fundamental 132 Rio de Janeiro. Ementa: 1. Arguição de descumprimento de preceito fundamental (ADPF). Perda parcial de objeto. Recebimento, na parte remanescente, como ação direta de inconstitucionalidade. União homoafetiva e seu reconhecimento como instituto jurídico. Convergência de objetos entre ações de natureza abstrata. Julgamento conjunto. Encampação dos fundamentos da ADPF $n^{\circ} 132-R J$ pela ADI $n^{\circ}$ 4.277-DF, com a finalidade de conferir "interpretação conforme à Constituição" ao art. 1.723 do Código Civil. Atendimento das condições da ação. [...]. Brasília: Supremo Tribunal Federal, [2011]. Relator Min. Ayres Britto. Julgamento em 05 de maio de 2011. Disponível em:

http://redir.stf.jus.br/paginadorpub/paginador.jsp?docTP=AC\&doclD=628633 Acesso em: 20 mar. 2019.

BRASIL. Supremo Tribunal Federal (STF). RE 846102 / PR - PARANÁ. Decisão recurso extraordinário. Constitucional. Reconhecimento de união estável homoafetiva e respectivas consequências jurídicas. Adoção. Ação Direta de Inconstitucionalidade n. 4.277. Acórdão recorrido harmônico com a jurisprudência do Supremo Tribunal Federal. Recurso extraordinário ao qual se nega seguimento. [...]. Brasília: Supremo Tribunal Federal, 2015. Relatora Min. Cármen Lúcia. Julgamento em 05 de março de 2015. Disponível em:

http://www.stf.jus.br/portal/jurisprudencia/visualizarEmenta.asp?s1=000042964\&base=bas eMonocraticas Acesso em: 17 mar. 2020.

CARVALHO, Nathalie de Paula. Uma Análise do Ensino Jurídico no Brasil. Revista Jurídica da UNI7. Fortaleza: Centro Universitário 7 de Setembro, v. 8(1), p. 249-260, 2011. Disponível em:

https://www.uni7.edu.br/periodicos/index.php/revistajuridica/article/view/125 Acesso em: 28 ago. 2019. doi: https://doi.org/10.24067/rju7,8.1:125

DIAS, Maria Berenice (coord.). Diversidade Sexual e Direito Homoafetivo. 3. ed. rev., atual. e ampl. São Paulo: Editora Revista dos Tribunais, 2017.

DIAS, Maria Berenice (coord.). BARRETTO, Fernanda Carvalho Leão (org.). Intersexo: aspectos: jurídicos, internacionais, trabalhistas, registrais, médicos, psicológicos, sociais, culturais. São Paulo: Thomson Reuters Brasil, 2018. 
DO ESPIRITO SANTO, Eliseu Roque. Homossexualidade: psicanálise, religião e educação. Revista Internacional Interdisciplinar INTERthesis, Florianópolis: Universidade Federal de Santa Catarina, v. 14, n. 3, p. 88-103, set. 2017. ISSN 18071384. Disponível em: https://periodicos.ufsc.br/index.php/interthesis/article/view/18071384.2017v14n3p88/34880 Acesso em: 12 set. 2019. doi: https://doi.org/10.5007/18071384.2017v14n3p88

FARIA, Adriana Ancona de. Reflexões sobre a Educação Jurídica: Desafios ao Ensino e à Pesquisa. Academia. Buenos Aires, Argentina: Revista sobre enseñanza del Derecho, año 12, número 24, 2014. ISSN 1667-4154. Disponível em:

http://www.derecho.uba.ar/publicaciones/rev academia/revistas/24/reflexoes-sobre-aeducacao-juridica.pdf Acesso em: 21 jul. 2019.

LANZ, Letícia. O corpo da roupa: a pessoa transgênera entre a transgressão e a conformidade com as normas de gênero. Uma introdução aos estudos transgêneros. 2. ed. Curitiba: Movimento Transgente, 2017.

PEPÊ, Albano M. B.; HIDALGO, Daniela B. M. Da disciplina à transdisciplinaridade pela transgressão waratiana: uma releitura heideggeriana do ensino jurídico. 2013. Seqüência, Florianópolis: Universidade Federal de Santa Catarina, v. 34 n. 66, 2013. ISSNe 21777055. Disponível em: http://dx.doi.org/10.5007/2177-7055.2013v34n66p283 Acesso em 21 jul. 2019.

SALDÃNA, Paulo. Saiba como surgiu o termo "ideologia de gênero": Movimento conservador tem origem religiosa e vê "ameaça à família" em discussões sobre gênero. Folha de São Paulo on line, 23.out.2018 às 2h00. Disponível em:

https://www1.folha.uol.com.br/cotidiano/2018/10/saiba-como-surgiu-o-termo-ideologia-degenero.shtml Acesso em: 19 jun. 2019.

SANTOS, Jean Wyllys de Matos. A farsa da "ideologia de gênero". Folha de São Paulo, São Paulo, Opinião, 02h00min, 15/03/2016. Disponível em:

https://m.folha.uol.com.br/opiniao/2016/03/1749913-a-farsa-da-ideologia-de-genero.shtml

Acesso em 25 ago. 2019.

SILVA, Regina Beatriz Tavares. Meninos vestem azul e meninas vestem rosa. São Paulo: ADFAS, 2019. Disponível em: http://adfas.org.br/2019/01/09/meninos-vestem-azule-meninas-vestem-rosa/ Acesso em 21 jul. 2019.

SILVA, Regina Beatriz Tavares. Neutralidade sexual: a Ideologia de Gênero. [2016]. Disponível em: http://adfas.org.br/2016/11/30/neutralidade-sexual-a-ideologia-de-genero/ Acesso em 26 jun. 2019.

VECCHIATTI, Paulo Roberto lotti. Manual da homoafetividade: da possibilidade jurídica do casamento civil, da união estável e da adoção por casais homoafetivos. 2. ed. rev. e atual. Rio de Janeiro: Forense; São Paulo: Método, 2012. 


\section{NOTAS}

Germana Parente Neiva Belchior

Doutora em Direito pela Universidade Federal de Santa Catarina (UFSC)

Centro Universitário 7 de Setembro (UNI7), mestrado e graduação em Direito, Fortaleza-CE, Brasil

germana_belchior@yahoo.com.br / germana.belchior@uni7.edu.br

(1) https://orcid.org/0000-0003-1870-8958

\section{Marcos Heleno Lopes Oliveira}

Mestrando em Direito Privado pelo Centro Universitário 7 de Setembro (UNI7)

Centro Universitário 7 de Setembro (UNI7), mestrado em Direito, Fortaleza-CE, Brasil

marcoshlo@bol.com.br

(1) https://orcid.org/0000-0001-5619-0577

Endereço de correspondência do principal autor

Germana Parente Neiva Belchior,

Rua Tenente Benévolo, N. 1900, Ap. 2000, Bairro: Meireles, CEP: 60.160-041, Fortaleza - CE, Brasil.

\section{AGRADECIMENTOS}

Não se aplica

\section{CONTRIBUIÇÃO DE AUTORIA}

Concepção e elaboração do manuscrito: G. P. N. Belchior, M. H. L. Oliveira

Coleta de dados: G. P. N. Belchior, M. H. L. Oliveira

Análise de dados: G. P. N. Belchior, M. H. L. Oliveira

Discussão dos resultados: G. P. N. Belchior, M. H. L. Oliveira

Revisão e aprovação: G. P. N. Belchior, M. H. L. Oliveira

Caso necessário veja outros papéis em: https://casrai.org/credit/

CONJUNTO DE DADOS DE PESQUISA

Todo o conjunto de dados que dá suporte aos resultados deste estudo foi publicado no próprio artigo.

\section{FINANCIAMENTO}

Não se aplica.

\section{CONSENTIMENTO DE USO DE IMAGEM}

Não se aplica.

\section{APROVAÇÃO DE COMITÊ DE ÉTICA EM PESQUISA}

Não se aplica.

\section{CONFLITO DE INTERESSES}

Não se aplica.

\section{LICENÇA DE USO}

Os autores cedem à Revista Internacional Interdisciplinar INTERthesis os direitos exclusivos de primeira publicação, com o trabalho simultaneamente licenciado sob a Licença Creative Commons Attribution (CC BY) 4.0 International. Esta licença permite que terceiros remixem, adaptem e criem a partir do trabalho publicado, atribuindo o devido crédito de autoria e publicação inicial neste periódico. Os autores têm autorização para assumir contratos adicionais separadamente, para distribuição não exclusiva da versão do trabalho publicada neste periódico (ex.: publicar em repositório institucional, em site pessoal, publicar uma tradução, ou como capítulo de livro), com reconhecimento de autoria e publicação inicial neste periódico.

\section{PUBLISHER}

Universidade Federal de Santa Catarina. Programa de Pós-graduação Interdisciplinar em Ciências Humanas. Publicação no Portal de Periódicos UFSC. As ideias expressadas neste artigo são de responsabilidade de seus autores, não representando, necessariamente, a opinião dos editores ou da universidade.

\section{EDITORES}

Javier Ignacio Vernal e Silmara Cimbalista

\section{HISTÓRICO}

Recebido em: 15.09.2019 - Aprovado em: 30.03.2020 - Publicado em: 30.04.2020 